\title{
Complex coastal protective measures to protect the sandy beach
}

\author{
Yuriy Dreizis ${ }^{1, *}$ and Vladislav Kostin ${ }^{2}$ \\ ${ }^{1}$ Sochi State University, Plastunskaya str., 94-1, 354000, Sochi, Russia \\ ${ }^{2}$ Kherson State University, Universitetskaya str. 27, 73003, Kherson, Ukraine
}

\begin{abstract}
The environmental impact of the engineering project was taken into account when carrying out comprehensive studies of shore protection engineering measures for the Lazurnoye region of the Kherson region of Ukraine on the north-western coast of the Black Sea. The optimal configuration of hydrotechnical structures are choosen to protect the beach in the region of the incoming wave impact. The entire coastline of the Lazurnoye region is about 3000 meters. In the course of modelling and numerical experiments, the transfer of bottom sediments to the coast, the evolution of the coastline and beaches, and other coastal processes were studied. The project of comprehensive coastal protection of the Lazurnoye region, presented on the basis of mathematical and hydraulic modelling, has allowed the development of engineering solutions that meet coastal protection and environmental requirements. The most expedient variant of coastal protective measures was the creation of a system of the beachprotected structures - capes from sections of the permeable slope-steps designs with wave damping chambers. The presented research results and the solution of many problems of the dynamics of the coastal zone of the sea can be considered as an attempt to manage coastal processes on rather large and complex sections of the coast with a joint solution to the problems of hydraulic engineering, management of water quality in the coastal zone of the sea, and the choice of optimal options with the least impact on the environment.
\end{abstract}

\section{Introduction}

For many years, the engineering measures on the coast were connected only with the maintenance of problems of the direct coastal protection of separate sites or creation of local beaches for recreation purposes of particular customers. Often, coastal protective structures lead to disruption of natural water exchange, resulting in a deterioration in the quality of sea water. The reason of it is in the absence of an estimation of possible influence of engineering measures recommended by the projects on the environment and their fulfillment.

Some sea regions on the Black sea and other sea coast has the coast consisting mainly of sandy sediments with a diameter of particle from about 0.1 to $1.0 \mathrm{~mm}$. Sandy beaches may include a silt fractions and large pebbles up to boulders. The example of sandy beach is shown in figure 1.

\footnotetext{
${ }^{*}$ Corresponding author: yurid2006@yandex.ru
} 
In fact, the coastal slope is composed of particles of sand, gravel and pebbles that are heterogeneous in size. Beach material originally participates in on shore - off shore transport of deposits. In the future, deposits form a structure that ultimately tends to the state of the dynamic equilibrium structure. Deposits also participate in longshore transport, moving along the formed cross structure. Deposits tend to sort by particle size along the body structure of the beach during a storm [1-7].

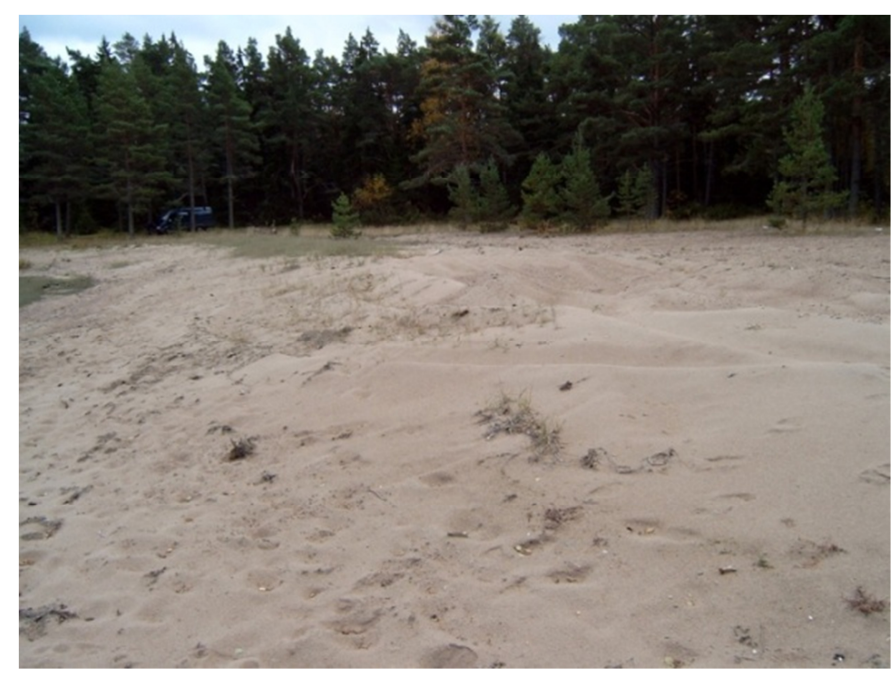

Fig. 1. The example of the sandy beach.

The scheme of sediment movement particles in horizontal and inclined bottom is shown in figure $2[1,3]$.

a)

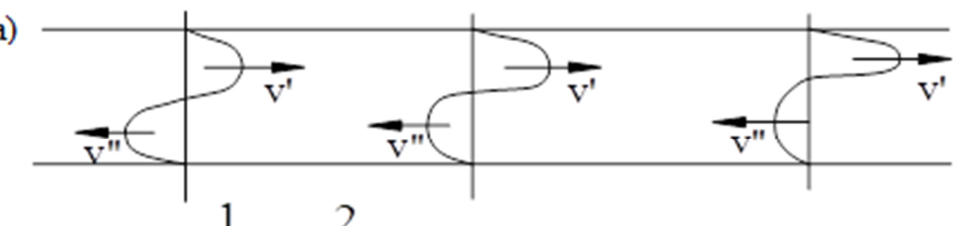

b)

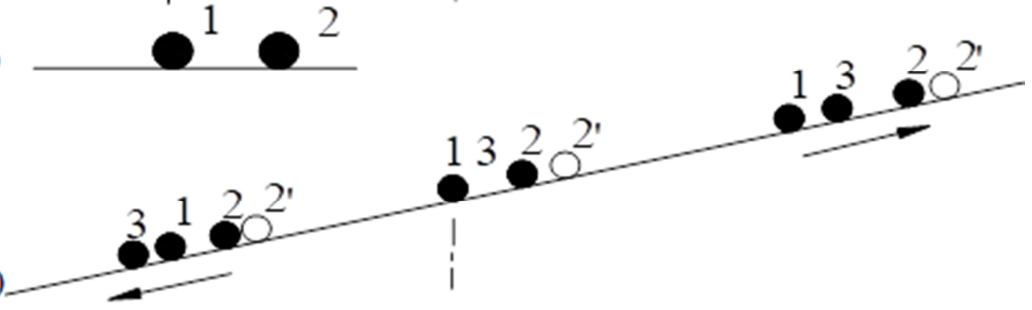

Fig. 2. The scheme of sediment movement particles in horizontal and inclined bottom.

Deposits also participate in longshore transport, moving along the formed cross structure, which is shown in figure 3 [1-3]. 


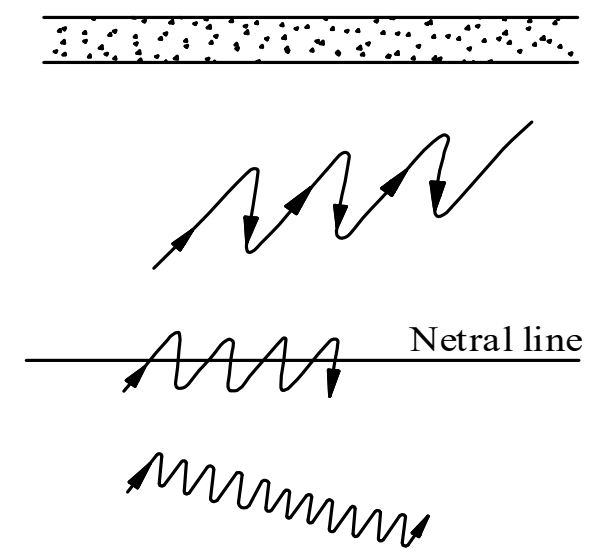

Fig. 3. Moving of deposits in longshore transport.

The various calculated curves used in engineering calculations to estimate the costs of alongshore sand and gravel deposits [1-7]. This applies to the estimates of the integral transport of sediment in the longshore direction, and the estimates of the local longshore sediment transport and transverse directions. This situation is caused by the fact that most of the dependencies for the transport of sediment in the coastal zone of the sea waves and currents include the calibration coefficients. In addition, the dynamic processes of interaction of waves with steep banks and sandbanks have significant differences, which must be taken into account when calculating sediment transport.

The different composition and particle size of sediment motion on the slopes move in different ways.

Existing models for predicting the coastline and beach dynamics, sediment transport models in the coastal zone of the sea take into account homogeneous sediments in the fractional structure in the calculations (sand, pebble, gravel). However, real beaches, an underwater coastal slope, and blurry materials to replenish beaches from landmines often have an uneven size distribution. [4-8].

Thus, the maximum average particle diameter of the material is observed somewhat closer to the coast from the upper boundary of the movement of breaking waves. When moving towards the beach, the average particle size of the material decreases.

Such redistribution of particles of a material is typical for sandy beaches and beaches from a pebble. In some parts of the coastal zone, this redistribution of particles leads to the formation of a structure that combines in the lower underwater part with sand and above the upper profile of the beach, first pebbles and then gravel.

Therefore, for more accurate calculations of sediment transport, prediction of the dynamics of heterogeneous grain composition of the beach material and shoreline is necessary to develop models and methods of calculation. Such methods should take into account the heterogeneous composition of the beach material

At the same time, it was found that on sandy beaches there is a distribution of grain particles by size along the transverse profile of the beach with a general tendency to increase the average grain size to the top line of rolling waves.

Deposits tend to sorting according to the size of particles along a body structure of the beach during a storm.

The attempt to reduce the influence of the engineering projects on an environment was undertaken during fulfillment of complex researches on coastal protective engineering measures for region on the beach coast of the Black sea. Lazurnoye is the settlement of Kherson region of the Ukraine on the north-western coast of the Black sea (figure 4) [9]. 


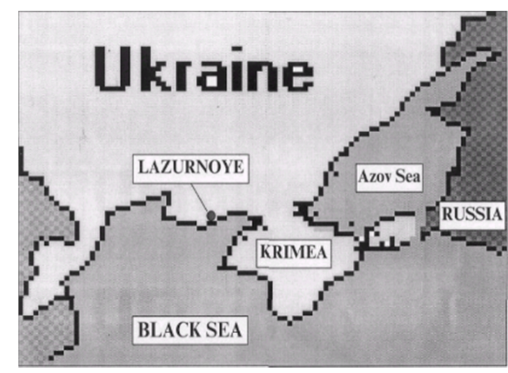

Fig. 4. The scheme of the studied site.

The project of complex protection of coasts of the Lazurnoye region, presented on the basis of mathematical and hydraulic modeling, made it possible to develop engineering solutions that meet both shore protection and environmental requirements.

Investigated site of the coastal zone in the region of Lazurnoye is within limits of abrasion-accumulative system Tendra-Dgarylgach on the northwest coast of the Black sea (distance $-3000 \mathrm{~m}$ ). The data of long-term supervision testify that process of the digression of the coastal line at Lazurnoye up to $60 \mathrm{~cm}$ per year is predetermined by historical development of the coastal zone. Therefore, construction near the coastline always hides some danger to the facility under construction. This happened with the spa-hotel built here, holiday houses, a place for which was chosen without taking into account coastal dynamics.

The previously undertaken passive coastal protection in the form of a structure from a concrete slope and a stone outline of a berm with a supporting vertical wall only contributed to the leakage of a small natural sandy beach and unhindered contact of the breaking waves with the shore.

Assessing the impact of design decisions on coastal processes and determining the optimal configuration and parameters of coastal protective and hydraulic engineering structures in order to reduce the environmental impact of their construction was an object of research. The problem of reconstruction of existing beaches and their use for recreation has also been solved.

The aim of the research is to develop recommendations to protect sandy beaches and improve their recreational characteristics based on engineering solutions in the field of coastal hydraulic engineering.

Processes under research are [8-16]:

- wave refraction;

- wave-breaking currents and transport of sediment;

- deformation of the coastal line;

- change of water quality in the coastal zone;

- influence of longitudinal and cross structures on these processes;

- the choice of optimal variant of coastal protective measures.

The solution of problems and the selection of optimal options for shore protection measures were carried out on the basis of numerical and physical modeling of coastal processes.

To perform engineering projects that are associated with different hydraulic engineering and coastal protective solutions, it is necessary:

- to calculate the sediment transport in the coastal zone,

- to predict the dynamics of the coastal line, including near constructions,

- to determine the amount of restoration of beaches eroded by waves, etc. 


\section{Results and discussion}

Wave parameters (direction, exceedance, height, length, a corner between front of waves and a coastal line), a corner between front of waves and a coastal line, bottom characteristics and the average diameter of the beach material are needed for calculation of hydraulic processes in coastal zone.

\subsection{Site hydrodynamic characteristics}

Data of wave, current and beach characteristics are shown in Table 1 and Table 2 [9].

Table 1. Dangerous wave direction and speed of wind (once in 25 years).

\begin{tabular}{|c|c|c|c|c|}
\hline Direction & W & SW & S & SE \\
\hline Speed of wind & 20 & 20 & 21 & 19 \\
\hline
\end{tabular}

Table 2. Data of waves (on deep water).

\begin{tabular}{|c|c|c|c|c|}
\hline Exceedance & \multicolumn{2}{|c|}{ 1 time in year } & \multicolumn{2}{c|}{ 1 time in 50 year } \\
\hline Direction & $\mathrm{H}_{\mathrm{m}}, \mathrm{m}$ & $\mathrm{L}_{\mathrm{m}}, \mathrm{m}$ & $\mathrm{H}_{\mathrm{m}}, \mathrm{m}$ & $\mathrm{L}_{\mathrm{m}}, \mathrm{m}$ \\
\hline $\mathrm{S}-\mathrm{E}$ & 0.2 & 6.2 & 0.4 & 9.3 \\
\hline $\mathrm{S}$ & 1.4 & 43.2 & 3.1 & 89.1 \\
\hline $\mathrm{S}-\mathrm{W}$ & 1.7 & 53.2 & 3.6 & 119.2 \\
\hline $\mathrm{W}$ & 1.6 & 49.4 & 3.4 & 106.6 \\
\hline
\end{tabular}

$H_{m}$ is the average height of the wave, $\mathrm{L}_{\mathrm{m}}$ is the average wavelength.

The dynamics of the beach is investigated by a model based on the conservation of the material flow of the beach, and its corresponding accumulations and losses on the transverse structure of the beach and along it, including in areas of coastal structures.

The charge of deposits is defined under the modified power formula of longshore transport of deposits. The formula takes into account a refraction of suitable waves:

$$
\begin{aligned}
& Q=K_{\bmod } \cdot P_{l}, \quad P_{l}=\frac{\rho_{w} \cdot g^{2}}{64 \pi} H_{0}^{2} T K_{R}^{2} \sin 2 \alpha_{b}, \\
& \alpha_{b}=z \alpha_{0} ; \quad z=0,25+5,5 \frac{H_{0}}{L_{0}}, \quad K_{R}=\left(\frac{\cos \alpha_{0}}{\cos \alpha_{b}}\right)^{1 / 2}
\end{aligned}
$$

where: $\mathrm{H}_{0}$ - height of waves on deep water; $\mathrm{T}$ - the average period of waves, $\mathrm{K}_{\mathrm{R}}-$ factor of a refraction; $\mathrm{K}_{\bmod }$ - the factor determined by Ackers-White technique; $\mathrm{P}_{1}-$ a longshore component of wave energy; $\alpha_{0}-$ a corner between front of waves and a coastal line on deep water; $\alpha_{b}$ - a corner between front of breaking waves and a coastal line.

The choice of formula (1) is caused by the fact that it is possible to estimate the flow rate according to this formula and with a small slope characteristic of shaved banks. The sediment consumption on the models was determined by measuring the volume of material deposition in the accumulation zone.

The data on currents of sediment deposit are shown in Table 3. 
Table 3. Data of the nature supervision.

\begin{tabular}{|c|c|}
\hline Source of sediment & Volume of the beach creation fraction \\
\hline Rock abrasion material and site coast material & $132000 \mathrm{~m}^{3} /$ year \\
\hline Underwater slope of the coastal zone & $315000 \mathrm{~m}^{3} /$ year \\
\hline Average annual budget & $447000 \mathrm{~m}^{3} /$ year \\
\hline $\begin{array}{c}\text { The longshore flow of sediment - about } 7000 \mathrm{~m}^{3} / \text { year (from east to west) } \\
\left(12000 \mathrm{~m}^{3} / \text { year from east to west and } 5000 \mathrm{~m}^{3} / \text { year from west to east) }\right.\end{array}$ \\
\hline $\begin{array}{c}\text { Average total deficit of sediment within the limits of the system makes } 52,5 \mathrm{~m}^{3} \\
\text { on } 1 \mathrm{~m} \text { of the coastal line }\end{array}$ \\
\hline $\begin{array}{c}\text { Average width of a beach on the majority of investigated sites is } 5-10 \text { meters, in some areas pro- } \\
\text { tected by coastal structures, it reaches } 27-40 \mathrm{~m}\end{array}$ \\
\hline Average diameter of sand is $0.38 \mathrm{~mm}$ \\
\hline Underwater slope is complicated by underwater shafts, departing from a coast \\
under a corner $1.5-5^{\circ}$. \\
Extent of shafts is from 3.5 up to $5.5 \mathrm{~km}$. Volume of sand in a body of shafts is $500000 \mathrm{~m}^{3}$ \\
\hline
\end{tabular}

\subsection{Mathematical modeling of wave, current and shore line evolution}

The studied objects vary greatly in morphometric characteristics and applicability.

The solution of the tasks and the selection of the best options for shore protection measures were carried out on the basis of numerical and physical modeling of the processes of wave refraction, wave-breaking currents and sediment transport, evolution of the coastal tooth, changes in the water quality in the coastal zone, the influence of structures on coastal dynamics.

Waves, current fields, beach development, and water exchange for numerical modeling were also tested in several configuration options for coastal structures.

Wave refraction in the coastal zone. The wave refraction in the shallow water computed by the large-scale, wave-current interaction model and model of irregular wave distribution on coastal slope and in the surf zone. The model includes a modified criterion for the destruction and allowance for the mutual influence of waves and the flows induced by them. The result is a parameter of the waves acting on the structure.

Transport of sand sediment. The modified formulas used for calculation of the long shore flow of sediment [2-6, 9].

Wave-induced current. Model of the current based on the numerical integration of the depth-averaged hydrodynamic equation for irregular waves.

Shoreline evolution. The position of the beach shoreline is determined by a model based on the nonlinear sediment balance equation from the sediment balance equation [11-16]:

$$
\frac{\partial y}{\partial t}=-\frac{1}{D} \frac{\partial Q}{\partial x}
$$

where: $\mathrm{y}$ - variable width of a beach which is measured from an axis $\mathrm{x}$, a parallel average coastal line, D - active depth of a beach. It is defined as limiting depth of water on which there is a movement of a material of a beach, $\mathrm{x}$ - distance along the appropriate axis, $\mathrm{t}-$ time. The circuit of a problem is shown in Figure 5: 


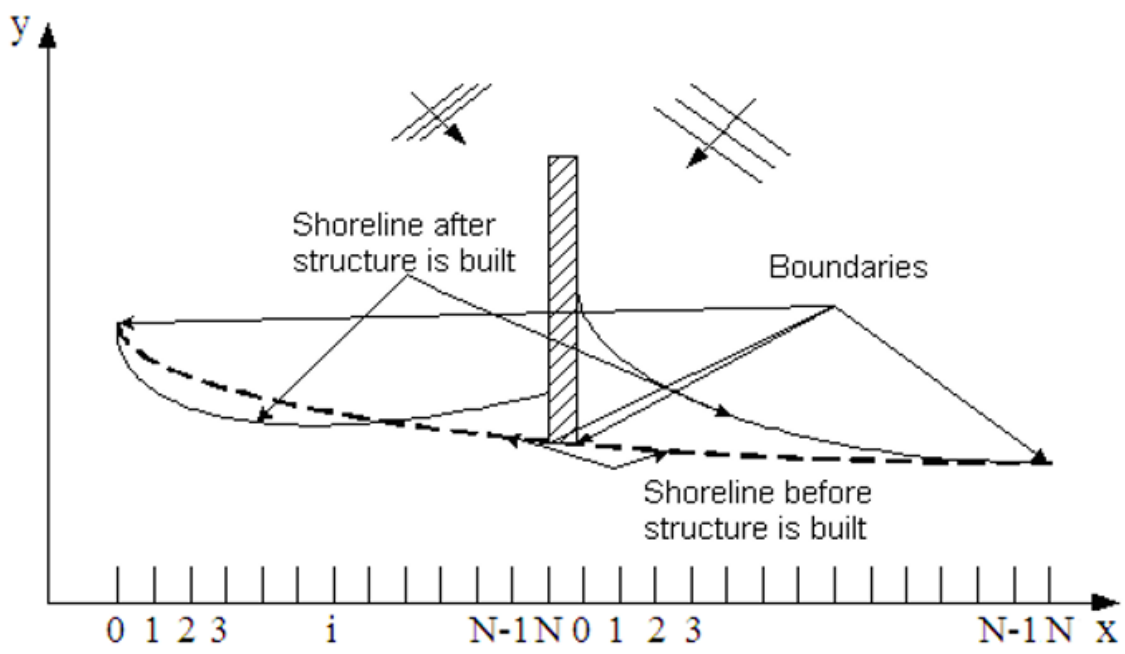

Fig. 5. The circuit of a problem of rearrangement of a coast in vicinity of cross constructions.

To define the optimal length of the grown for the beach protection in the Lazurnoye region, the modelling of the beach evolution in the Lazurnoye region under the storm action have been carried out. The applied mathematical model is the quasi 1-D model based on the nonlinear equation of the sediment balance [11-16]

$$
\frac{d y}{d x}=\frac{2 Q \cot \left(2 \alpha_{b}\right)}{d_{b}\left[1+(d y / d x)^{2}\right]} \frac{d^{2} y}{d x^{2}}
$$

where $Q=$ longshore transport rate of sediment in square meters per second; $\mathrm{y}(\mathrm{x}, \mathrm{t})=$ variable beach distance from the $\mathrm{x}$-axis ( $\mathrm{x}$-axis is a reference axis parallel to the average shoreline); $\mathrm{t}=$ time; $\mathrm{d}_{\mathrm{b}}=$ breaker water depth, $\alpha_{\mathrm{b}}=$ breaker wave crest angle.

External borders from both sides of a construction are set on distances where influence of a construction on transport of deposits is not enough. On these borders, the charge of deposits is defined under the modified power formula (1) that takes into account a refraction of waves. Other boundary conditions are set directly from both sides of a construction.

For an impenetrable construction, the charge of deposits on a construction is equal to zero. Otherwise, this charge should be determined. Initial position of a beach is set according to measurements.

Influence of length of a construction on an arrangement and size of a washout zone is taken into account by inclusion in calculation of dynamics of a coastal line of diffraction of waves, which arises in a zone of a wave shadow of a construction.

In addition, the permeability of designs of a cross construction affects washout of a beach and its site. To account for the diffraction of waves, the developed methodology for calculating the diffraction coefficient of waves and the angle of approach of waves on the fault line is used. In the formula of calculation of the longshore components of wave energy, the factor of diffraction $K_{D}$ is introduced additionally.

The factor takes into account the change of height of a wave along its crest in a zone of diffraction of waves behind a construction. Thus, the factor of refraction $K_{R}$ in the formula is replaced with combined factor $K_{R} K_{D}$.

For definition of factor of diffraction $K_{D}$, it is offered to use approximation which is presented in Figure 6. According to approximation, factor $K_{D}$ changes linearly from 0.33 at a line of a construction up to 0.575 on border of a wave shadow. Further, it changes linearly 
from 0.575 up to 1.0 ; last value is reached on crossing of the beam, which is taking place through a head of a construction on the angle $\alpha_{b}$. The decision will be in good agreement with the well-known Penny-Price policy decisions $[11,16]$.

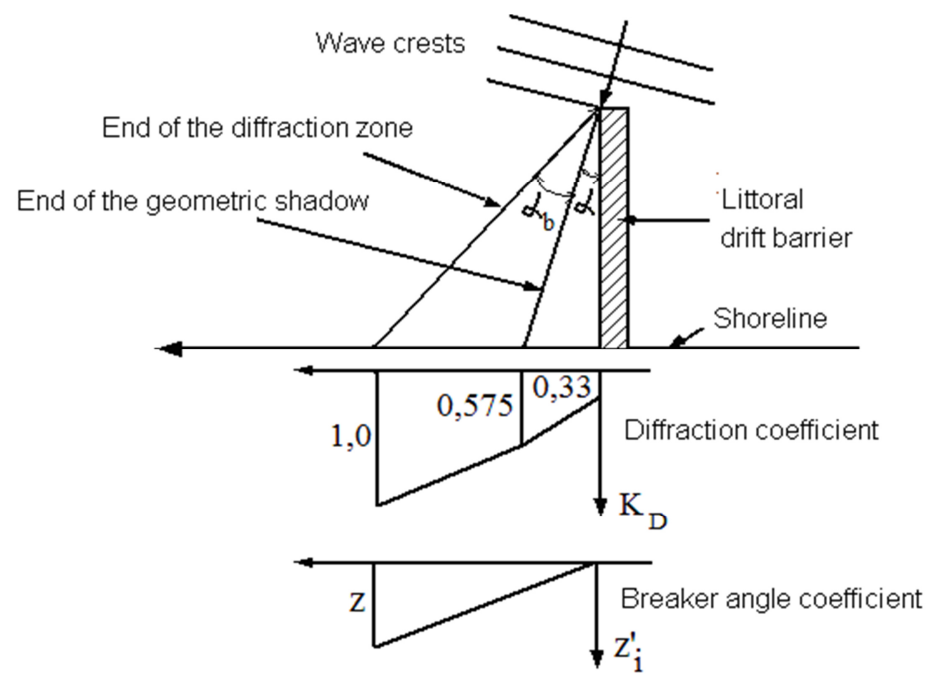

Fig. 6. The proposed approximation for the diffraction coefficient and determination of the angle of approach of waves on the breaking line.

The corner on a breaking line in the field of diffraction is defined by introduction of factor $Z_{D}$ in each point $\mathbf{i}$ of diffraction areas [11-16]:

$$
\alpha_{b}=z_{i}^{\prime} \alpha Z_{D i}
$$

where represents value $z$ in a point $i$.

According to the formula (9), factor $Z_{D}$ is defined as:

$$
Z_{D i}=\frac{\sin \left(z_{i}{ }_{i} \alpha_{0}\right)}{\sin \left(z \alpha_{0}\right)}
$$

Thus, $Z_{D}$ represents the relation of the longshore charge in a point $i$ inside a diffraction zone and on border of a diffraction zone. The factor varies from 0 up to 1 (from line of constructions where the size of a longshore charge is equal 0 , up to border of a zone of diffraction where a longshore charge is defined by the CERC formula). Size $Z_{D}$ depends on size $Z_{i}^{\prime}$, which varies linearly from 0 at a construction up to $\mathrm{z}$ on border of a zone of diffraction (fig. 6). Thus, boundary conditions for factor $Z_{D}$ are satisfied.

Introduction of factor of diffraction and change of a corner of the approach of waves on a line of wave breaking in a zone of diffraction $\left(Z_{D}\right)$ is carried out by multiplication calculated with the help of model of discrete charges of deposits in different points along a coast and at the different moments of time.

In the used model, the effect of the length of the structure on the location and size of the wash pit is taken into account by including in the calculation the diffraction of waves occurring in the zone of the wave shadow of the structure, as well as by the influence of the permeability of the transverse structure. The diffraction coefficient is proposed to be determined on the basis of the approximation [12-16]. 
The equations are solved numerically using a method of final differences for the given initial and boundary conditions. This decision allows receiving distribution of a stream of deposits and position of a coastal line in units of a discrete grid along a coastal line and with discrete time step. The Krank-Nicholson scheme is used for linearization and numerical integration.

\subsection{Experimental facility}

Series of experiments on rearrangement of a structure and dynamics of a coastal line of sandy beach in conditions of influence of cross-coastal protection constructions were carried out.

The experiments of the physical modeling were carried out in the wave basin of trapezium form (bases are 41 and 25 meters and the height is 31.5 meters) and height of walls is 1.7 meters with a several scales for objects of studies. An investigated site of the coastal zone is $3000 \mathrm{~m}$. Several physical models determined by soluble problems and investigated sites of the coastal zone were studied. When researching stability of the sand beaches in the Lazurnoye region, deformed modeling (various vertical and horizontal scales) was used. Therefore, for modeling, the site of the coastal zone in Lazurnoye on a vertical scale was $1: 30$, and on a horizontal scale - 1:86. Scale of modeling of waves period is $1 / 5.5$. Scale of modeling of sediment flow is $1 / 2220$. Time scale processing of a model by excitement is $1 / 100$.

The moved wave marker generates waves. Waves were of the SW and W directions. Extreme waves in excess of 0.05 are used to calculate wave attenuation, medium waves in excess of 0.50 are used to model water exchange, and waves in excess of 0.30 are used to model beach development and longshore sediment transport.

The models were wash-out from the sand with a diameter of $0.36 \mathrm{~mm}$.

Duration of each experiment is 6 hours.

The study of each object was carried out for several dangerous wave directions.

The following parameters are measured during the tests:

- waves, evolution of the beach and current velocities in the Lazurnoye region;

- influence of the difference structures on evolution of the beach and water exchange at the coastal area of the object of studies;

- determination of the optimal configuration and parameters of structures.

The several configuration variants of the shoreline and several variants of the beachprotected structure on the Lazurnoye coast are studied. The wave-induced currents and water exchange near the study coastal structures are tested; the objects were investigated for several dangerous wave directions.

The studies were conducted for various options of coastal protection structures and their layout.

The best results of the beach protection are obtained in case with the use of the permeable coastal structures.

\subsection{Evolution of the beach and coastal structures in the Lazurnoye region}

Options for coastal protection measures to stabilize the beach and increase it for recreational opportunities have been investigated based on existing experience of protecting a coastal strip of a similar type, such as:

- free artificial beaches,

- traditional cross designs (a system of moles of the different length and configuration),

- long shore permeable wave damping structures of a various design and different characteristics of the wave damping (slope-steps, piles and others), 
- system of artificial capes from a permeable slope-steps designs [9].

In the course of modeling and computer experiments, the transfer of bottom sediments to the coast, the evolution of the coastline and beaches, and other coastal processes were studied.

The analysis of nature observation data showed that there is a deficit of sediment in the coastal course in the studied area.

The results of experiments to simulate the initially planned version of measures to protect the coast in the form of a system of stone-mooring moles from 40 to $80 \mathrm{~m}$ long (large stone of $0.5 \mathrm{~m}$ ) with significant artificial spills from the beach into the span compartments showed the possibility of stabilizing the beach on the studied site without guarantee of prevention of the local erosion in the following areas. The hydrodynamic parameters of the structures of permeable piles with a wave chamber are most close to the parameters in the section zone of the most effective designs created on a nature - free beach.

The proposed option for creating a system of artificial capes from permeable slope-step structures (Fig. 7 and Fig. 8) with small volumes of outflows in bays formed between the capes at the study site contributes to the passage of the coastal stream by sludge and stabilization of the beach with a width sufficient for relaxation.

Creating a free artificial beach requires large amounts of material formed by the beach, and there are technical and economic problems for this option.

It is proposed to create a system of structures of a new type - capes from unpressurized step structures with chambers.

The most appropriate option for shore protection measures in the studied area is to create a system of beach-protected structures of a new type - capes from the section of permeable inclined-step structures with wave damping chambers. The cape has the shape of a trapezoid with a large base in the longitudinal direction near the protruding wall of $120 \mathrm{~m}$ and the base on the side of the sea step of $65 \mathrm{~m}$ in the plan. The width of the steps of the spans along the sea and the sides is $8 \mathrm{~m}$. The length of the cape along the axis from the coast to the sea is $50 \mathrm{~m}$, the peak mark is $2.6 \mathrm{~m}$. Capes are located along the protected section of the coast at a distance between the axes of 200-220 m. Beach material spills out in the bays between the capes. And the width of the sides is provided in the bays of 30-40 m (Fig. 7 and Fig. 8).
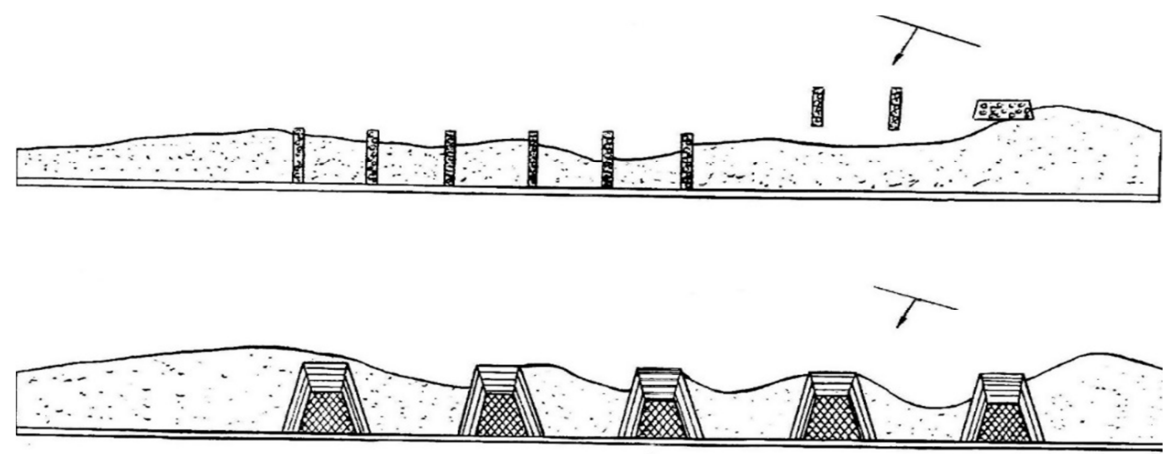

Fig. 7. Schematic diagram of variants of the coastal protective measures in the Lazurnoye region (1system of the stone-sketch moles, 2 - permeability capes design). 


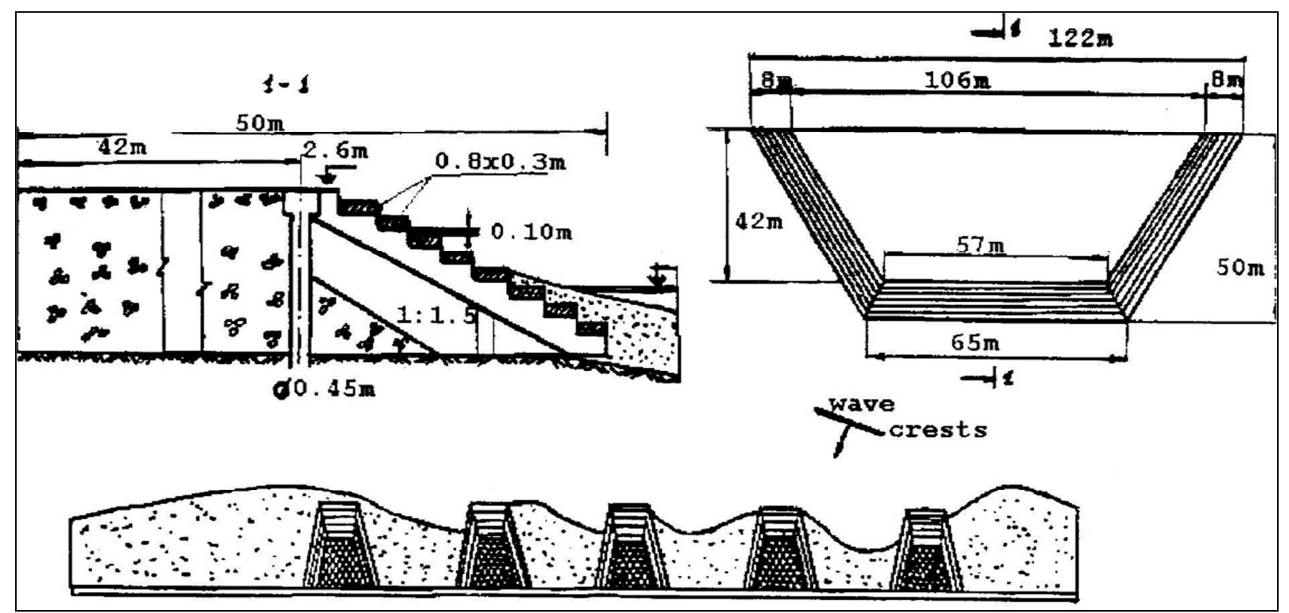

Fig. 8. Schematic diagram of permeability capes design.

This recommended option for the restoration and stabilization of the beach strip compared to other options is more material and comprehensive in terms of construction technology, but has a number of significant advantages:

- the system of capes does not interfere with longshore moving of the sediment, which eliminates the threat of the formation of local weak erosion in neighboring areas,

- the permeable design of capes with the wave damping chambers promotes reduction of the wave influence on the artificial beaches in bays, raising their stability,

- the use of existing sand selected in the preparation of construction sites under capes for pouring the beach in the bays reduces the volume of imported beach molded material,

- the whole area of capes, which makes 0.4 ha for each cape, can be used for purposes of recreation, that in conditions of the deficit of the near coast area and increase of cost of ground, especially in the resort zones, gives positive social and economic benefit;

- the system of the cape - bay is close to natural morphological structures on the sand beaches, is ecologically pure complex from the architectonic point of view and harmoniously fits into the natural landscape.

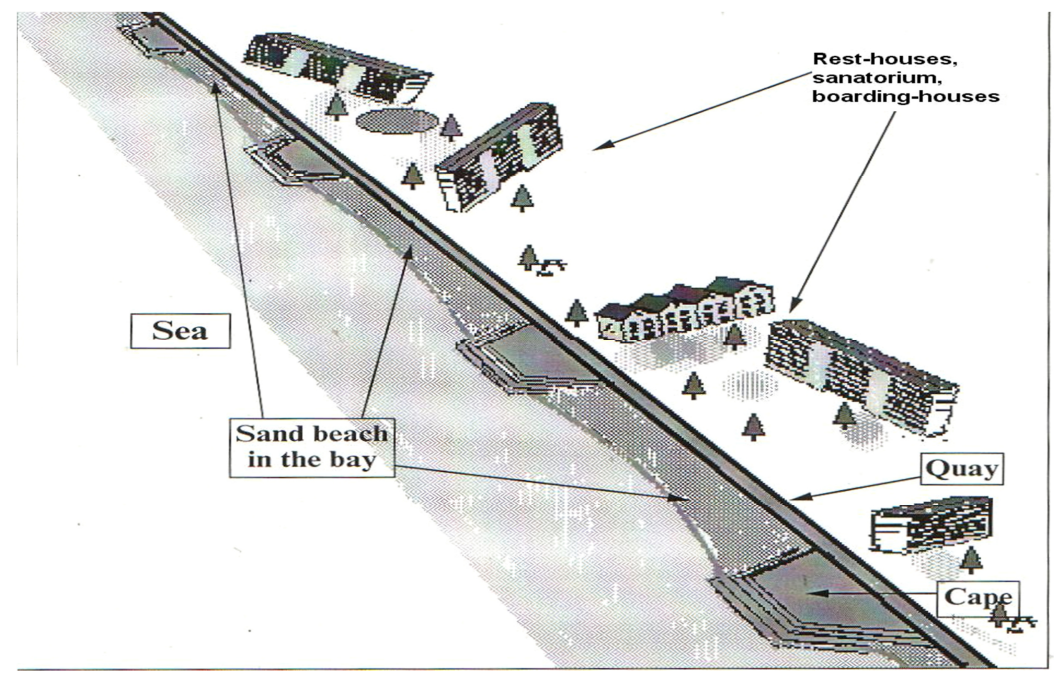

Fig. 9. System of the beach-protected structures - capes from the section of the permeable slope-steps designs (scheme in the plan). 


\section{Conclusions}

The options for choosing new coastal structures gave the best results for protecting the beach, water exchange and can be used in coastal protection practice.

The most appropriate option for shore protection measures was to create a system of shore protection structures: capes from sections of permeable slope-steps designs with wave damping chambers.

Based on this study, the following conclusions are made:

1. The results of comprehensive studies and the solution of the problems of the dynamics of the coastal zone of the sea can be considered as a possible attempt to manage coastal processes in large sections of the coastal zone, for which a complex of hydraulic and environmental problems is associated with economic and recreation problems, water quality management in the sea coastal zone, assessment of the impact of adopted engineering decisions on the environment.

2. The applied study technique, which includes the mathematical and physical modelling, may be used for designing of the others similar coastal structure system.

The presented research results and the solution of many problems of the dynamics of the sea coastal zone can be considered as an attempt to manage coastal processes on rather large and complex sections of the coast with a joint solution to the problems of hydraulic engineering, management of water quality in the coastal zone of the sea and the choice of optimal options with the least impact on the environment.

\section{References}

1. P. Ackers, W. White, Proc. of the ASCE 99(HY11), 2041-2060 (1973)

2. J.S. Schoonees, A.K. Theron, J. Coastal Engineering 19, 1-25 (1993)

3. I.O. Leontiev, Coastal dynamics: Waves, currents, sediment flows (GEOS, Moscow, 2001)

4. I. Kantardgi, S. Antsyferov, Proc. of Int. MEDCOAST Workshop on Beaches of the Mediterranean and the Black Sea: Dynamics, regeneration, ecology \& management, 133-144 (2002)

5. I.G. Kantarji, E.V. Bondarreva, V.V. Weitman, Yu.I. Dreizis, MGSU Bulletin 1, 90$106(2010)$

6. S.M. Antsyferov, I.G. Kantarzhi, Calculation of concentration of sediments suspended by waves spreading on the course. Water farm, ports and port facilities, offshore construction facilities (Moscow State Construction University, Association of Construction Universities, Moscow, 2010)

7. I.G. Kantarzhi, M.S. Antsyferov, Oceanology 45(2), 173-181 (2005)

8. Yu.I. Dreizis, E.V. Bondareva, I.G. Kantardgi, European Researcher 76(6-1), 1105 1108 (2014)

9. Yu.I. Dreizis, V.O. Kostin, Proc. VI International Conference on Coastal and Port Engineering in Developing Countries (COPEDEC VI), 186-203 (2003)

10. I.G. Kantardgi, Yu.I. Dreizis, L.V. Prokhoda-Shumskikh, Proc. of the 2nd Int. Conf./Workshop on the State-of-the-Art of ICM in the Mediterranean and the Black Sea: Immediate Needs for Research, Education / Training \& Implementation, 205-210 (2008)

11. E.V. Bondareva, I.G. Kantardgi, Yu.I. Dreizis, Proc. of Works of the Scientific and Practical Conference of Grant Holders of RFFI and Administration of Krasnodar Ter- 
ritory "Contribution of Fundamental Scientific Research to the Development of Modern Innovative Economy of Krasnodar Territory", 47-48 (2009)

12. E. Bondareva, I. Kantardgi, Proc. of 9-th Int. Conf. on the Mediterranean Coastal Environment (MEDCOAST 09) (2009)

13. E.V. Bondarreva, I.G. Kantarzhi, Hydrotechnical construction 12, 33-40 (2009)

14. Yu.I Dreyzis, E.V. Bondareva, I.G. Kantardgi, Proc. of the 11-th Int. Conf. on the Mediterranean Coastal Environment (MEDCOAST 11) 2, 747-759 (2011)

15. Yu.I. Dreizis, E.V. Bondareva, I.G. Kantardgi, Proc. of the 8th Int. Conf. on Coastal and Port Engineering in Developing Countries (COPEDEC 2012) 20 (2012)

16. E.V. Bondareva, D.S. Fedorov, Modeling of Artificial Intelligence 3(7), 186-191 (2015) 